\title{
21. COMMISSION DE LA LUMINESCENCE DU CIEL
}

\section{Report of Meetings}

President: D. Barbier.

SECRETARY: W. Steiger.

\section{First Meeting, 26 August 1964}

The meeting was called to order at $10^{\mathrm{h}} 45^{\mathrm{m}}$ by the President. A few moments of silence were observed in memory of H. F. Siedentopf and L. Vegard.

The President reported that a symposium on Theoretical Interpretations of Upper Atmosphere Emissions organized by J. Chamberlain had been held during the period 25 June I 962 to 29 June at Gif-sur-Yvette (near Paris), France.

Discussion of the Draft Report was initiated. Link suggested the addition of the following statement: 'Les mesures crépusculaires au cours de l'AGI et de la CGI (1957-1959) à Lomnický Stit montrent le plus souvent la constance pendant le crépuscule $\left(8^{\circ}<u<18^{\circ}\right)$ de l'intensité de 5577 avec quelques rares renforcements [14I]'.

The President reported that, due to the death of Professor Siedentopf, a report on the zodiacal light has not been completed.

The President announced the names of the new officers of Commission 21 to be proposed to the General Assembly for approval, as follows:

President: F. E. Roach

Vice-President: M. Huruhata

He proposed following names for the Organizing Committee, which were approved by members.

Organizing Committee: J. W. Chamberlain (U.S.A.), J. Dufay (France), V. I. Krassovsky (U.S.S.R.), M. Nicolet (Belgium), F. Link (Czechoslovakia), M. Ingham (U.K.).

The following new members of the Commission from countries not members of the IAU were proposed by President Barbier and approved by the membership: Tcheng Mao Lin (Peking), Nguyen Huu Doan (South Vietnam).

The President has proposed for membership of Commission $2 \mathrm{I}$ and received the approval of the appropriate National Committees, the following: D. Hunten (U.S.A.), L. Wallace (U.S.A.), E. V. Fesenkova (U.S.S.R.), M. Ingham (U.K.).

Additional names have been proposed, but the approval of the National Committee has not yet been received: J. Christophe-Glaume (France), J. W. Weinberg (U.S.A.).

At the Berkeley meeting a committee within Commission 2I was created to deal with the zodiacal light with Professor Siedentopf as chairman. The President raised the question of the desirability of a new committee on zodiacal light. J. Kaplan supported the establishment of such a committee. F. Link inquired where problems concerning twilight scattering belonged. The President replied that they are not presently the concern of any particular commission. Roach suggested that, as the new President, he would be glad to set up a committee on zodiacal light (atmospheric scattering being included), if the Commission members so desired. R. Robley proposed that the Gegenschein should be included in the zodiacal light committee's responsibility. The Commission approved the establishing of this committee. 


\section{SCIENTIFIC DISCUSSION}

Two scientific reports were presented, one by W. Steiger and one by M. Dufay. Abstracts of these reports follow.

\section{SOME OBSERVATIONS OF $6300 \AA$ AIRgLOW at HaLEAKala}

\section{W. Steiger}

Observations of night airglow in $6300 \AA$ as well as $5577 \AA$ and $5893 \AA$, have been carried out continuously since May I96I at Haleakala, Hawaii. The work reported here is the joint effort of F. E. Roach, W. Brown, and W. Steiger.

\section{A. The relationship between $Q\left(6_{3} \circ 0\right)$ and the F-region ionosphere}

On the basis of a production mechanism for $6300 \AA$ involving a charge exchange and dissociative recombination with the constituents $\mathrm{O}_{2}, \mathrm{~N}_{2}$, and $\mathrm{O}^{+}$, a formula for the intensity of the $6300 \AA$ airglow can be deduced of the form

$$
Q\left(6_{3} \circ 0\right)=K\left(f_{0} F_{2}\right)^{2} \mathrm{e}^{-\left(\frac{h^{\prime} F-h_{0}}{H}\right)}
$$

Comparison with observed $Q(6300)$ shows that a formula of the form $Q(6300)=A+B E$, where $E=\left(f_{0} F_{2}\right)^{2} \mathrm{e}^{-\left(\frac{h^{\prime} E-h_{0}}{H}\right)}$, fits the data quite well when $A$ and $B$ are constants determined by the slope and intercept of a regression line between $Q\left(6_{3} 00\right)$ and $E$. On individual nights the correlation coefficient between $Q(6300)$ and $A+B E$ is often around 0.9 and occasionally as high as 0.98 . The constants $A$ and $B$ change from night to night. The values found using the entire data for 93 nights from July i96r to July i962 are $A=26.8$ and $B=$ 4.2 with a correlation coefficient of 0.74 .

It was found that $Q(5577)$ was in general not correlated to $Q(6300)$ but on a few nights there were pronounced enhancements in both 6300 and 5577. On one of these nights it was possible to fit empirical formulas to both the 6300 and 5577 emissions and thus it was possible to produce maps of the peak electron density and the virtual height of the $F$-region of the ionosphere covering the entire sky visible to the photometer.

\section{$B$. The relationship between $Q(6300)$ and the geomagnetic field}

Daily 5-hour averages of $Q(6300)$ were plotted against the corresponding planetary magnetic index $K_{p}$. There was no evidence of any correlation. Even when the seasonal variation in $Q\left(6_{300}\right)$ was removed or when only the most active period of the year was considered, there was no significant correlation.

\section{The alignment of $Q\left(6_{3} 00\right)$ isophotes}

An analysis of 4617 isophote maps showed that 3015 displayed a 'spotty' character while I 602 displayed an 'aligned' character. Of these latter, 728 occurred between $2 \mathrm{I}^{\mathrm{h}} 55^{\mathrm{m}}$ to $02^{\mathrm{h}} 55^{\mathrm{m}}$ free of any twilight effects. Their alignments were in all directions but showed a very high preponderance with an azimuth in the range $28 \mathrm{I}^{\circ}$ to $290^{\circ}$. The azimuth of the horizontal component of the magnetic field is $\mathrm{II}^{\circ}$. It is suggested that there is a weak but pronounced magnetic control resulting in the alignment of $Q\left(6_{300}\right)$ isophotes perpendicular to the geomagnetic field.

\section{The seasonal variation of $Q(6300)$}

The position of the maximum $Q(6300)$ along the meridian just at the end of twilight has been determined for $I 49$ nights over a period of $I$ year. It is found that this maximum is to the 
north of the zenith in summer and moves to the south in winter, in phase with the declination of the Sun.

A plot of 3 -month running means of the average zenith $Q(6300)$ during the interval $22^{\mathrm{h}} \circ 0^{\mathrm{m}}$ to $03^{\mathrm{h}} 00^{\mathrm{m}}$ local time, for the year $196 \mathrm{I}-62$, showed a pronounced maximum in September and a minimum in the months of January, February, and March.

\section{ÉTUDE SPECTROSCOPIQUE DE LA LUMINESCENCE DE GAZ RARÉfiés EXCITÉS \\ PAR CHOC DE PARTICULES}

\section{Maurice Dufay}

Une étude de la luminescence de gaz raréfiés excités par choc de particules a pu être récemment entreprise à l'Institut de Physique Nucléaire de la Faculté des Sciences de Lyon, grâce à l'obligeance de Monsieur Sarazin, Directeur de l'Institut.

Les particules (protons ou ions $\mathrm{H}_{2}^{+}$) sont issues d'un accélérateur Häfely I $\mathrm{MeV}$. Après filtrage magnétique, le faisceau passe dans une chambre d'expérience en traversant deux petits diaphragmes permettant d'assurer un pompage différentiel entre l'accélérateur et la chambre. La pression dans celle-ci peut varier de $10^{-5} \mathrm{~mm} \mathrm{Hg}$ à $0.5 \mathrm{~mm} \mathrm{Hg}$. Un spectrographe à réseau et optique de Schmidt (ouverture $F / \mathrm{I}$, dispersion $30 \AA / \mathrm{mm}$ dans le second ordre) est placé latéralement.

Les premières expériences ont été faites sur l'air, l'oxygène pur et l'azote pur avec des protons ou des ions $\mathrm{H}_{2}^{+}$accélérés sous une tension de 500 o0o volts, le débit variant entre Io et $5 \circ \mu \mathrm{A}$.

Le spectre de l'azote dans la région $3500-5500 \AA$ comporte essentiellement les bandes du premier système négatif de $\mathrm{N}_{2}^{+}$et celles du deuxième positif de $\mathrm{N}_{2}$. Comme l'ont déjà remarqué d'autres, les bandes de $\mathrm{N}_{2}-2 p$ dont l'excitation doit faire intervenir les électrons secondaires, ont une faible intensité à faible pression $(\mathbf{r} \mu \mathrm{de} \mathrm{Hg})$ et deviennent aussi intenses que celles de $\mathrm{N}_{2}^{+}$à la pression de $0.25 \mathrm{~mm}$ de $\mathrm{Hg}$. Sur les spectres de l'air on observe en outre plusieurs raies de $\mathrm{N}$ I et $\mathrm{N}$ II qui semblent disparaître ou devenir très faibles avec l'azote pur. L'excellente définition des spectrogrammes obtenus permet de voir la structure de rotation des bandes de $\mathrm{N}_{2}^{+}$et de mesurer la température de rotation qui a été trouvée égale à $73^{\circ} \mathrm{K}$.

Dans la même région spectrale, le spectre de l'oxygène pur ne comporte que les multiplets de OII ainsi que quelques raies de OI. Les premiers spectres obtenus dans la région $5500-6500 \AA$ semblent indiquer une anomalie dans la répartition des intensités des bandes de $\mathrm{O}_{2}^{+}$observées.

\section{Second Meeting, 27 August 1964}

Presiding: F. E. Roach, Commission 21 Vice-President.

SPECIAL SESSION ON ZODIACAL LIGHT

$F$. E. Roach-Three fundamental problems were mentioned:

(1) The physical nature of the zodiacal cloud,

(2) The distribution of the zodiacal cloud throughout the solar system,

(3) Astronomical origin and history of the zodiacal cloud.

There followed a discussion and comparison of three studies in which Roach has been involved:

1937-Elvey and Roach (LVR), $A p .7 ., 85,213,1937$.

1954-Roach, Pettit, Tandberg-Hanssen and Davis (RPTD), Ap. F., rrg, 253, 1954.

1964-Smith, Roach and Owen (SRO), In press. 
It was concluded that the three sets of observations could be rationalized if the following relationship holds among the respective absolute calibrations:

$$
0.7 \mathrm{LVR}=\mathrm{RPTD}=\mathrm{SRO}
$$

It was speculated that an excess of light observed by SRO at high ecliptic latitudes might be due to a dust belt near the Earth, possibly constrained by the Earth's magnetosphere. Whipple and Weinberg commented that it is unlikely that the dust cloud around the Earth could be solely responsible. Photometric zenith observations in Colorado and in Hawaii by Roach and Smith were presented. It was noted that such observations may assist in establishing absolute calibration standards in night sky photometry. Mention was made of the problem of estimating the galactic light with particular reference to the uncertainty introduced by the widely divergent star-count statistics which have been published.

F. $L$. Weinberg-A summary report was given on the current status of zodiacal light research with emphasis on the large discrepancies which exist in both the radiance and polarization parameters. These discrepancies were discussed in terms of their effect on the following: the distribution of zodiacal light over the entire sky, the density distribution of the zodiacal cloud in a direction perpendicular to the ecliptic, the relative numbers of electrons and dust particles in the interplanetary space, the kinds of dust particles which are most numerous, their number and mass densities, and the fact that both absolute calibration and separation of components are involved in these discrepancies.

Some recent results from the Haleakala Observatory were discussed:

(I) the orientation of the plane of polarization agrees with theory in the plane of the ecliptic but not at high ecliptic latitudes,

(2) no polarization was detected at the Gegenschein.

E. P. Ney-Recent balloon observations of the zodiacal light by Ney and colleagues were presented. The instrumental techniques used were described in detail and results on the inner zodiacal light (radiance and polarization) were given. The measured polarizations are not as high as those found by Blackwell and Ingham or by Elsässer, but the results agree with those of Weinberg. Photos were shown of the airglow layer as photographed by Astronaut Cooper from a satellite and of the airglow, starlight, and zodiacal light as recorded by a photographic system suspended from a balloon during a solar eclipse.

R. Dumont-A discussion was given of photoelectric measurements of the zodiacal light at Haute-Provence using a Cassegrain optical system. The measured zodiacal light radiances are $90 S_{10}$ (celestial pole) and $75 S_{10}$ (ecliptic pole) and the airglow continuum in the zenith varies from $15 S_{10}$ to $75 S_{10}$.

F. Link-Primary and secondary scattering in twilight observations was discussed with particular reference to the effect of a high level terrestrial dust cloud (Bull. astr. Inst. Csl., r3, 129, 1962).

$F$. Whipple-Whipple reviewed the current status of thinking on the mass range and the origin of the zodiacal cloud. In the mass range of $\mathrm{I}$ g to $\mathrm{IO}^{-2} \mathrm{~g}$, it is believed that $90 \%$ (and probably $99 \%$ ) is of cometary origin; only approximately $\mathrm{r} \%$ of asteroidal debris. Mention was made of the dust in the Earth's immediate vicinity. In the discussion Weinberg pointed out that the enhancement of dust near the Earth would be only a factor of 10 rather than 1000 (with respect to the interplanetary medium) if very small particles exist in large numbers as suggested by a comparison of recent observations with theoretical calculations.

L. Aller-Aller gave a report of theoretical calculations by his colleages, O'Mara and Little, on the Mie scattering of various models of the interplanetary matter. The study which included some of Richter's experimental data is similar to that of Giese and Siedentopf. Using the 
observational results of Weinberg, Aller and colleagues found that the best interpretation occurs for dielectric particles (in agreement with conclusions already reached by Weinberg).

Aller emphasized the importance of obtaining reliable zodiacal light data on the Stokes parameters in the region of elongation between $160^{\circ}$ and $180^{\circ}$. Weinberg noted that he had just completed a I-year study of the zodiacal light with particular emphasis on this region and that the results would be available soon. As both Aller and Weinberg pointed out, the most important regions of zodiacal light for inferring the nature of the interplanetary dust are very close to the Sun and very far from it (near the Gegenschein).

Miscellaneous-There seemed to be general acceptance by the group that the contribution of free electrons to the zodiacal light is small. It was mentioned (by Elsässer) that if very small particles are assumed to be the principal material of the zodiacal light, this would require a complete revision of our interpretation of the physical nature of the $F$-corona. 